time was significantly longer (24mins vs 40 mins, $p=0.04$ ), althought this group tended to have more unwell patients (ASA grade) and a higher difficulty grade of ERCP ( $p=0.06$ and 0.05 respectively). There were no signifcant differences in frequency of adverse events between PCPS and standard sedation $(p=0.87)$. Also, there were no significant differences in recovery time, although Aldrete scores tended to be higher in the PCPS group. Endoscopist rating of how sedation was tolerated was significantly higher in the PCPS group ( $p=0.04)$. 2 cases that had failed under standard sedation were subsequently completed using PCPS

Conclusion PCPS is an effective method of sedation for ERCP. This small UK based study shows that PCPS is at least as safe as standard sedation techniques, even when used in complex procedures in severely unwell patients. In the future, with appropriate training and governance, PCPS might be utilised without anaesthetic support

Disclosure of Interest None Declared.

\section{PWE-039 INFORMING PATIENTS AND THE MULTI DISCIPLINARY TEAM OF A DIAGNOSIS OF GASTRO-INTESTINAL MALIGNANCY}

doi:10.1136/gutjnl-2013-304907.328

1,"J E Rimmer, ${ }^{2} \mathrm{~J}$ Hookway, 'S P Dunlop. ' Gastroenterology Department; ${ }^{2}$ Endoscopy Department, Derriford Hospital, Plymouth, UK

Introduction The management of gastro-intestinal (GI) malignancy is largely determined by multi-disciplinary team (MDT) discussion, where members have not met the patient. The quality of information given to the patient immediately following endoscopy, and subsequently to the MDT, is variable.

Methods A 3 month retrospective audit of all outpatient endoscopic diagnoses of upper and lower GI malignancies at Derriford Hospital, Plymouth. The endoscopy report (Endosoft), endoscopy care pathway and medical notes were reviewed. Information provided regarding the description of pathology; post endoscopic patient discussion; GI Cancer Nurse Specialist (CNS) involvement and request for staging imaging was interrogated. Inpatients were excluded.

Results There were 65 patients with GI malignancy (oesophagogastric cancer [OGC] $\mathrm{n}=24$; colorectal cancer [CRC] $\mathrm{n}=41$ ). For patients with confirmed OGC the report recorded suspected malignancy in 19/24 (79\%). Post endoscopy patient discussion was recorded on the report in $7 / 19$ (37\%); patient informed \& recorded only in the nurse's care pathway in 5/19 (26\%); no evidence of discussion with patient in $7 / 19$ (37\%). GI CNS involvement was documented on the report in $5 / 19(26 \%)$; the report documented requesting of staging imaging by the endoscopist in 10/19 (53\%). For patients with confirmed CRC the report recorded suspected malignancy in 33/41 (80\%). Post endoscopy discussion was recorded on the report in $10 / 33$ (30\%); patient informed \& recorded only in the nurse's care pathway in $13 / 33$ (39\%); no evidence of discussion with patient in 10/33 (30\%). GI CNS involvement was documented in $15 / 33$ (45\%). The report documented requesting of staging imaging by the endoscopist in $22 / 33$ (67\%).

Conclusion The MDT relies upon patients being informed of their suspected diagnosis, and accurate endoscopic documentation in order to make informed decisions and to allow direct referral to Surgical and Oncological specialities. However, a significant proportion of patients with upper and lower GI cancer leave the endoscopy department without a diagnosis of suspected cancer being made, and even when it is suspected, are frequently not informed by the endoscopist.

Disclosure of Interest None Declared.

\section{PWE-040 PREVALENT ROUND STAGE SHIFT IN THE NATIONAL BOWEL CANCER SCREENING PROGRAMME IN WALES; DATA FROM THE FIRST 3 YEARS AT A SINGLE SCREENING CENTRE}

doi:10.1136/gutjnl-2013-304907.329

1."J J Hurley, ${ }^{2}$ A B Hawthorne, ${ }^{3} \mathrm{~J}$ Torkington, ' J Green, 'S Dolwani. 'Gastroenterology, University Hospital Llandough; ${ }^{2}$ Gastroenterology; ${ }^{3}$ Colorectal Surgery, University Hospital of UK, Cardiff, UK

Introduction Colorectal cancer screening is based on early detection of cancers and removal of premalignant polyps though this adenoma to carcinoma sequence is thought to progress over several years. The Bowel Screening Programme in Wales based on guaiac FOBt and colonoscopy for individuals resting positive began rollout in October 2008, with the aim of reducing mortality through cancer detection at an early stage. The aim of this study was to investigate whether screen detected cancers in Cardiff and the Vale of Glamorgan demonstrated any shift in the stage of cancer during the first three years of screening (initial prevalent round).

Methods Data was collected prospectively to compare the staging of colorectal cancer diagnosed in the BCSP with cancers diagnosed in the non-screening population in the same geographical region from 1st October 2008 to 31st December 2011. All information was cross checked with Cancer Registry data.

Results Screen detected cancer was found in 69 individuals (44 male, 25 female), with a positive predictive value of colonoscopy (after positive FOB testing) of $8.7 \%$. Complete clinical staging was available for all 69 individuals; two patients did not undergo surgical resection due to the presence of metastases after radiological staging. There were 696 non-screening detected cancers during the same time period. For the purposes of this analysis, polyp cancers (cancer that was removed by endoscopic means at the time of colonoscopy/flexible sigmoidoscopy) were included in Duke's stage A, except for one polyp cancer that required subsequent surgical resection and was staged as Duke's C1. The results are shown in table 1. Three-quarters of cancers diagnosed in the BCSP were Dukes A or B, compared to $44.1 \%$ in the non-screening population. Of Duke's D cancers, only $2.8 \%$ were diagnosed through screening, with $27 \%$ diagnosed in the non screening population $(p<0.0001)$.

Abstract PWE-040 Table 1 Stage of cancer diagnosed with comparable data from non-screening population

\begin{tabular}{llll}
\hline Stage & BCSP & Non-screening population & p Value \\
\hline Duke's A & $35(50 \%)$ & $115(16 \%)$ & $\mathrm{p}<0.0001$ \\
Duke's B & $14(25 \%)$ & $192(28 \%)$ & $\mathrm{p}=0.67$ \\
Duke's C1 & $11(16 \%)$ & $120(17 \%)$ & $\mathrm{p}=0.87$ \\
Duke's C2 & $4(6 \%)$ & $27(4 \%)$ & $\mathrm{p}=0.35$ \\
Duke's D & $2(3 \%)$ & $192(28 \%)$ & $\mathrm{p}<0.0001$ \\
Dukes unknown & - & $49(7 \%)$ & \\
\hline
\end{tabular}

Conclusion This data strongly supports significant stage shift of colorectal cancer even within the initial prevalent round in this single Bowel Cancer Screening centre in Wales that the benefits of screening may be demonstrable in outcomes at a relatively early stage of the programme.

Disclosure of Interest None Declared.

PWE-041 HISTOPATHOLOGICAL UNCERTAINTIES IN THE
MANAGEMENT OF EARLY COLORECTAL CANCERS
RESECTED THROUGH ENDOSCOPIC THERAPY

doi:10.1136/gutjnl-2013-304907.330

1."J J Hurley, 'M Morgan, ${ }^{2} \mathrm{G}$ Williams, 'S Dolwani. ' Gastroenterology, University Hospital Llandough; ${ }^{2 H i s t o p a t h o l o g y, ~ U n i v e r s i t y ~ H o s p i t a l ~ o f ~ U K, ~ C a r d i f f, ~ U K ~}$ 